\title{
EFFECTS OF ELEVATED TEMPERATURE ON THE MORTALITY AND METABOLISM OF PACIFIC REEF CORALS
}

\author{
by \\ STEPHEN L. COLES ${ }^{1)}$
}

\begin{abstract}
The upper thermal tolerance limits of subtropical (Hawaiian) and tropical (Enewetak) reef corals were determined both in the field and under laboratory conditions. Enewetak corals routinely withstand temperatures up to $34^{\circ} \mathrm{C}$ whereas similar exposure time at $32^{\circ} \mathrm{C}$ kill their Havaiian congeners. These differing upper thermal limits correspond to increases of $+4-5{ }^{\circ} \mathrm{C}$ above the annual water temperature maxima at each location. Reef coral temperature tolerance is therefore closely adapted to the ambient ocean temperature conditions of a geographic location..

Studies of temperature effect on reef coral photosynthesis $(P)$ and respiration $(R)$ also z..owed different patterns between locations. Same species showed greater autotrophic capability at elevated temperatures in Enewetak than Hawaii. Critical temperatures estimated as coinciding with $\mathrm{P}: \mathrm{R}$ ratio values minimal to support long term functional autotrophy were $2-5^{\circ} \mathrm{C}$ higher for Enewetak than Hawaiian specimens, closely corresponding to observed differences in upper thermal tolerance. Results support a hypothesis of temperature adaptation capability for reef corals and suggest that short term physiological tests can predict relative differences in temperature tolerance among coral species.
\end{abstract}

1) Hawaiian Electricity Environmental Department, Honolulu, Hawaii. 